\title{
Factors that Increase Active Participation by Higher Education Students, and Predict the Acceptance and Use of Classroom Response Systems
}

\author{
Mitja Dečman ${ }^{1}$ \\ ${ }^{1}$ University of Ljubljana, Faculty of Administration, Gosarjeva ulica 5, 1000 Ljubljana, Slovenia \\ Correspondence: Mitja Dečman, University of Ljubljana, Faculty of Administration, Gosarjeva ulica 5, 1000 \\ Ljubljana, Slovenia.
}

Received: April 18, 2020

Accepted: May 13, 2020

Online Published: May 14, 2020

doi:10.5430/ijhe.v9n4p84

URL: https://doi.org/10.5430/ijhe.v9n4p84

\begin{abstract}
An increasing number of studies have addressed and proved the positive impact of classroom response systems (CRS) on learning performance in active learning environments but few focus on the parameters for the adoption and use of this technology in the classroom. This paper reviews research that has tested the parameters that influence the acceptance and use of CRS in the higher education context by utilizing the Unified Theory of Acceptance and Use of Technology (Venkatesh, Morris, Davis, \& Davis, 2003). The research tested a set of hypotheses that predict the conditions under which CRS technology use was likely to emerge and persist in the active learning environment. The results highlight the importance of students' habit and performance expectancy on CRS use; the added construct of trust also indicates a significant influence on CRS use intention. The findings will better enable educators to effectively use CRS technology to support active learning.
\end{abstract}

Keywords: classroom response system, active learning, technology adoption, clickers, higher education

\section{Introduction}

Knowledge exchange has been an important goal of human civilization; in recent centuries, its objective has been to transmit as much knowledge as quickly as possible using technologies such as print media, radio, TV, and information and communications technology (ICT), including the Internet; however, this is not sufficient, people yearn to actively participate by means of live meetings, mail correspondence, the telephone, and, in the 21 th century, Internet technologies. Such development is also seen in the environment of education and knowledge transfer, whereby the unidirectional lectures of the past have been replaced by today's active and collaborative learning environments supported by a plethora of ICT (Kulikovskikh, Prokhorov, \& Suchkova, 2017); one such technology is the classroom response system (CRS), often referred to the educational environment as student response systems or even "clickers" (Chan, Borja, Welch, \& Batiuk, 2016).

CRS enables students to provide feedback to an educator using digital technology, usually anonymously form, where the educator and other students can react to such feedback. It is especially important in active learning environments where the goal of activities is for students to not only receive information but to also gain knowledge and to learn through participation (De Gagne, 2011; Stowell \& Nelson, 2007). It has great potential in large-audience environments (Hubbard \& Couch, 2018; Rivkin et al., 2013), such as large classrooms. Furthermore, such activation can also foster deeper learning, especially in higher education environments (Kulikovskikh et al., 2017; Rivkin et al., 2013). As stated by Lewis, Fretwell, Ryan, and Parham (2013), ICT-supported active learning has been researched extensively and is needed in higher education classrooms to best engage the current techno-savvy generation in the instruction-learning process. Contemporary students are eager to incorporate ICT to enhance their educational experience (Spark \& De Klerk, 2015; Werf \& Sabatier, 2009, p. 7) and achieve better results. CRS technology can renew, improve, and sometimes reinvent the learning landscape. It can be used formatively, e.g. to assess student understanding during lectures, and summatively, e.g. to formally evaluate student knowledge at the end of the lecture (Kay, 2009), or as part of the grading process. Furthermore, interactivity, participation, satisfaction, learning outcomes, and other classroom-related topics are affected by CRS (De Gagne, 2011). Research indictes that CRS utilization positively influences examination scores and learning performance (Andersson \& Palm, 2017; Bojinova \& Oigara, 2013; Castillo-Manzano, Castro-Nuño, López-Valpuesta, Sanz-Díaz, \& Yñiguez, 2016; Shapiro et al., 2017), but knowledge domain, class size and question types have to be considered (Hunsu, Adesope, \& Bayly, 2016). 
Resources are needed to successfully implement and use CRS in a higher education context, including: ICT equipment, e.g. hardware, software, licenses; time, e.g. lecture preparation, course redesign; and people, e.g. educating lecturers and students, providing IT support. Hence, it is essential that these CRS resources are utlized by students to improve their learning performance (Pituch \& Lee, 2006). To guarantee this, parameters that affect classroom interaction and participation should be studied, e.g. expectations regarding student participation in discussions, individual learning styles that impact involvement, communication and feedback mechanisms, student confidence in their interpersonal skills, and adaption and acceptance of educational ICT (DeBourgh, 2008). Many of these parameters have been researched using different ICT focused acceptance models, most often the Technology acceptance model (TAM) (Green, Chang, Tanford, \& Moll, 2015; Rana \& Dwivedi, 2016) and the Unified theory of acceptance and use of technology (UTAUT) (Cheung, Chan, Brown, \& Wan, 2016; Farag, Park, \& Kaupins, 2015; Spark \& De Klerk, 2015). However, although both models focus on factors such as usefulness, performance expectancy, ease of use, effort expectancy, social influence, and facilitating conditions, some important factors were not included: habit, price value, and hedonic motivation. These were subsequently incorporated in the adapted Unified theory of acceptance and use of technology 2 (UTAUT2) model (Venkatesh, Thong, \& Xu, 2012) and used in this research to fill the gap in the literature on CRS studies. Therefore, unlike prior studies, we used a reliable and valid measurement instrument (Kay \& LeSage, 2009). Existent research also considered trust to be an important element in CRS adoption and was included in this research because it relates to people's need to control or understand the social environment in which they interact (Esteva Armida, 2008); the positive impact of trust on IT use had also been evidenced by different researchers (Pavlou, 2003; Singh \& Sinha, 2020; Wu \& Chen, 2005). To address aforementioned research gaps, this study was guided by the following objectives:

- to detect and explore the influence of different socio-technical parameters on student behavioral intention to use CRS in active learning environments;

- to develop and validate a framework model that validates key parameters for the successful introduction and use of CRS in active learning environments by extending the existing general ICT acceptance and use framework.

The research employed clickers and smartphone-based CRS applications for social science degree courses that promote active learning and subsequently collected data from users by means of a survey questionnaire to empirically test this framework.

\section{Theoretical Background}

\subsection{Classroom Response Systems}

Classroom response systems have been in use in educational environments since the 1960s (Black \& Wiliam, 1998). More specifically, they first appeared as voting machines at universities in the United States in the form of fixed buttons and phone dial pads on student seats (Judson \& Sawada, 2002). Subsequently, response submission activity was further advanced by the use of information technology, including "clickers", usually in the form of small remote-control devices. The latest generation of these systems enables students to use their own smart phone devices as clickers, enabling them to send a response using mobile applications, web browsers, or short text messages (SMS). Clickers are often used in line with the "buy your own device" concept in the higher education setting (Hung, 2017); students buy or rent clickers for a period of one or more years, link the devices to their student digital identities, and use them as a reliable means of identification. In this manner, they can link their CRS device activity to their grade records. Technological advances have also overcome the main barrier to the widespread introduction of CRS into classrooms in recent years, namely internet connectivity and hardware devices with easy-to-use interfaces (Castillo-Manzano et al., 2016). In contrast to the original clickers, today's CRS are multifunctional devices capable of sending much more than binary responses, e.g. numeric answers, rankings and full text responses.

CRS is primarily intended for activities that engage students in the learning process (Bojinova \& Oigara, 2013), that is where students do more than passively listen to lectures (Blasco-Arcas, Buil, Hernández-Ortega, \& Sese, 2013). Furthermore, CRS can be used as an in-class formative assessment tool for addressing each individual student, who otherwise might not be able to interact with the teacher. Black and Wiliam (1998, pp. 7-8) defined formative assessment as assessment "encompassing all those activities undertaken by teachers, and/or by their students, which provide information to be used as feedback to modify the teaching and learning activities in which they are engaged.". An instant reaction is appreciated because it improves course material understanding, increases class interaction, and enables opportunities to learn from one another (Cotner, Fall, Wick, Walker, \& Baepler, 2008). Although the main task of CRS is to better enable instant responses to questions, such systems' important functionalities often include correct answer projections, response statistics, graphical representation, a countdown timer, and databases of results for further analysis. Some technological solutions even contain elements of 
gamification, including the ability to compete and detect "most valuable players".

CRS impact has multiple dimensions. Firstly, based on the correctness of student answers, teachers will know whether students understand the content or not; they can redirect the learning process in line with responses, either by repetition, explanation, new data, or discussion. The latter enables the collective use of CRS and collaborative working, as stressed, for example, by US National Science Standards (Blasco-Arcas et al., 2013). Secondly, teachers can modify pace to better facilitate learning. Thirdly, it motivates because it allows individual student' voices to be heard. Furthermore, it is a great foundation for additional classroom discussion, and positively and strongly affects academic learning outcomes (Chien, Chang, \& Chang, 2016), encourages student participation (Efstathiou \& Bailey, 2012; Stowell \& Nelson, 2007), engagement (Blasco-Arcas et al., 2013; Hunsu et al., 2016; Lantz \& Stawiski, 2014), self-awareness and increased social facilitation (Oswald, Blake, \& Santiago, 2014), and attendance (Kay \& LeSage, 2009). Finally, CRS enables lectures to be appropriately divided into sections, and concluded with questions and discussion, thereby increasing and prolonging attention, which otherwise usually wanes within approximately twenty minutes (Burns, 1985).

\subsection{Active Learning}

Over the past decade active learning in the higher education context has been pushed forward, challenging lecturers to find ways to trigger and increase student participation (Tin, 2009). Defined as "the result of a deliberate and conscious attempt on the part of a teacher to cause students to participate overtly in a lesson" (Pratton \& Hales, 1986, p. 211), active learning refers to practices that engage students in the learning process, where students do more than passively listen to lectures (Blasco-Arcas et al., 2013). Modern technology that supports active learning enables better knowledge acquisition, improves critical thinking and bettert engagement with the material (Nicol, Owens, Le Coze, MacIntyre, \& Eastwood, 2018).

CRS can be especially beneficial in collaborative learning environments, where learning involves sharing knowledge, experiences and authority, whereby students teach and learn from each other (Blasco-Arcas et al., 2013). Collaboration among teachers and students using CRS motivates students to cooperate more dynamically and creates effective involvement with a topic's substance (Kay \& LeSage, 2009). Furthermore, CRS use in active learning activities, such as asking students to reach consensus in small groups, has proved to be effective in facilitating the positive outcomes associated with active learning (Daniel \& Tivener, 2016). Sun (2014) also discovered that polling activities reduce graduate student anxiety, improve student outcomes and hold student attention. CRS can improve teaching, although teachers may be reluctant to adopt it because of time constraints (Farag et al., 2015). Hunsu et al. (2016, p. 114) also state that to achieve higher order learning goals in classrooms, "emphasis must be placed on strategic lesson preparations as well as what goes on in class during instruction".

\subsection{Technology Acceptance and Use}

It is important to understand how such technology is accepted and what factors influence behavioral intention and use because CRS is a form of a technology usually used by specific types of user. Furthermore, it is important to analyze the different ICTs used in such environments as parallels can also be drawn from this. In the past, the UTAUT model (Venkatesh, Morris, Davis, \& Davis, 2003) was often used as the research framework for various studies measuring technology use and adoption (Maldonado, Khan, Moon, \& Rho, 2011). To overcome the limitations of the original UTAUT model, the authors of the model (Venkatesh, et al., 2003) developed the UTAUT2 model, added three new constructs: i) hedonic motivation, defined as the fun or pleasure derived from using technology; ii) price value, defined as user cognitive tradeoff between the perceived benefits of the technology and the cost of using it; and iii) habit as an antecedent of behavioral intention and use (Venkatesh et al., 2012). Researchers have utilized the UTAUT2 model's constructs in various contexts, sometimes extending the model with additional constructs, such as product quality, innovativness, resistance to change, technology, pedagogy and content knowledge.

The most recent research in the field has evidenced the influence of different constructs on the perception of adopting and using ICT therein. Mehta, Morris, Swinnerton, and Homer (2019) focused on e-learning and found that effort expectancy, performance expectancy, habit, and price value significantly influence behavioral intention; however, the influence of hedonic motivation and social influence was not detected. Raman and Don (2013) and Ain, Kaur, and Waheed (2016) analyzsed learning management systems and software, and evidenced the significant impact of performance expectancy, social influence and facilitating conditions on behavioral intention and use behaviour. However, whilst the former reseach found the impact of hedonic motivation on behavioral intention significant, the latter did not. In the context of mobile learning, Yang (2013) similary confirmed the significant influence of social influence, performance expectancy, hedonic motivation and price value on behavioral intention to actively engage in 
mobile learning, but not of effort expectancy and habit. Aria and Archer (2018) found performance expectancy, effort expectancy, and hedonic motivation to be significant positive factors influencing behavioral intention to learn by means of videos. Finally, Cheung et al. (2016) found that teachers' technological knowledge was positively correlated with effort expectancy, performance expectancy, and behavioral intention related to CRS use.

Our short literature analysis illustrates the applicability of the UTAUT and UTAUT2 frameworks in different educational contexts. However, literature on the adoption and use of CRS in classroom from students' perspectives is scarce. Furthermore, the number of studies focusing on use behavior is much lower when compared to those focusing on behavioral intention. Therefore, this study considers students' perspectives on CRS behavioral intention and use behavior and includes trust in technology as an additional important parameter.

\section{Research Model and Hypotheses}

In order to test the adoption and use of CRS technology in the higher education active learning environment, our work is based on the original UTAUT2 model with the added construct of trust (Figure 1) because trust in the reliability and accuracy of CRS is important due to it impact on active learning. Behavioral Intention (BI), our model's central variable, is influenced by six of the standard UTAUT2 model's latent variables, namely performance expectancy (PE), effort expectancy (EE), facilitating conditions (FC), social influence (SI), hedonic motivation (HM), and habit (HT); Price Value (PV), defined as the value for money paid for the technology, was omitted because the technology used was free of charge. BI further influenced Use Behavior (UB) together with two latent variables, i.e. FC and HT. The original UTAUT2 model also incorporated the influence of moderators such as age and experience, but students in our research study were all about the same age with no previous experience of using CRS. The proposed UTAUT2 model, including our ten hypotheses, is shown in Figure 1 below.

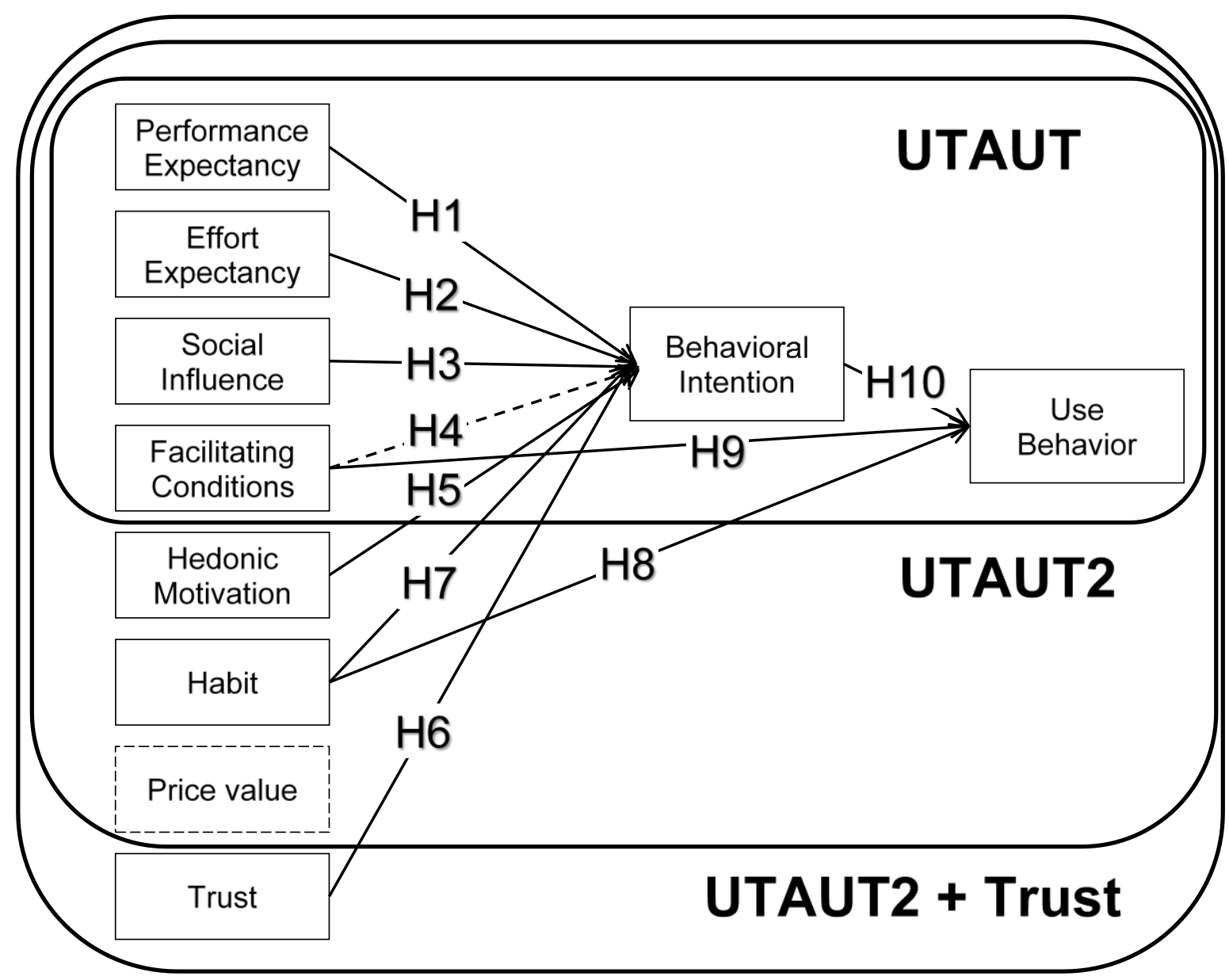

Figure 1. Proposed model based on the UTAUT2 model augmented with Trust and Price Value removed. 
Our research is based on the following 10 hypotheses:

H1: Performance Expectancy (PE) will have a significant positive influence on student BI.

$\mathrm{PE}$ is defined as the degree to which adopting CRS will improve student performance and is measured using four variables (see Appendix), and these aggregately state that users would adapt to technology if they believe it will help to improve their performance. PE was shown to be the strongest predictor of BI in the original UTAUT model (Venkatesh et al., 2003) and proved to be a significant factor in the UTATU2 model (Baabdullah, Alalwan, Rana, Kizgin, \& Patil, 2019; Yuan, Ma, Kanthawala, \& Peng, 2015). The important influence of PE on intention to use technology was confirmed in different educational environments, e.g. mobile learning (Yang, 2013), learning management systems (Ain et al., 2016), computer supported collaborative classrooms (Faizan, Pradeep Kumar, \& Kashif, 2016), software training systems (Chauhan \& Jaiswal, 2016), and e-learning (Mehta et al., 2019). Students found technology useful in their studies, most often with regard to CRS response results, which highlighted their level of understanding (Schackow, Chavez, Loya, \& Friedman, 2004). Moreover, Bright, Reilly Kroustos, and Kinder (2013) revealed that student response systems were useful starting points for the discussion of more complex matters.

H2: Effort Expectancy (EE) will be significantly and positively related to BI.

EE, the degree of ease associated with the use of technology (Venkatesh et al., 2012), is another confirmed influence factor; it is a vital construct in many technology acceptance and innovation diffusion models, and significantly affects BI. The latest research on video learning acceptance (Aria \& Archer, 2018), CRS use by teachers (Cheung et al., 2016), and software training (Chauhan \& Jaiswal, 2016) also evidence significant influence. Those accustomed to digital technology usually used CRS with less effort than those not, and this was especially true for young digital natives. CRS's use in higher education was especially related to the generation that had a preference for "digital literacy, experiential learning, interactivity, and immediacy" (Berry, 2009). Today, university students use digital technology as their primary means of communication (Lewis et al., 2013). Technology-based blended learning, flipped learning, and Massive Open Online Courses (MOOC) are also widely used in higher education environments.

H3. Social Influence (SI) will be significantly and positively related to BI.

SI, the degree of influence of others, e.g. other students, school friends, teachers and their beliefs on the use of CRS, is present in both UTAUT and UTAUT2, alongside PE, EE, and FC, and influences BI. SI, a subjective and social norm in earlier behavioral theories, is the degree to which users perceive that important individuals expect them to use said technology. Several studies in the educational context have reported SI's significant positive impact on the following: teacher perception of adopting new technology (Lewis et al., 2013), pre-service teacher acceptance of learning management software (Raman \& Don, 2013), student acceptance and use of computer-supported collaborative classrooms (Faizan et al., 2016), and student acceptance and use of m-learning (Yang, 2013). Collaborative learning, one of the most effective methods of active learning, occurs when students work together (Prince, 2004), influencing each other's learning, especially when combined with technology use (Stowell \& Nelson, 2007).

H4: Facilitating Conditions (FC) will not have a significant influence on student BI.

FC, "the degree to which an individual believes that a technical infrastructure exists to support use of the technology" (Venkatesh et al., 2003, p. 453), i.e. CRS, including training, support, and infrastructure, is concerned with resource, knowledge, and technology support sufficiency; a lack of assistance and/or timely support, the need for special knowledge about said technology, dissimilarity with other technologies used, and limited resources could hinder users in their acceptance and use of technology. The UTAUT model only suggested the influence of FC's influence on UB, the UTAUT2 model ascribes a direct relationship between FC and BI (Venkatesh et al., 2012): consumer FC existence varies significantly, e.g. when FC are managed by organizations, access is relatively equal, when not, access is variable. Because educational environments are managed they will conform with what was found by Ain et al. (2016) in their case study on student use of learning management systems (LMS), that the relationship between FC and BI was not supported; similar results were evidenced by Hsu (2013); Lewis et al. (2013) encountered a situation where the FC scale had not held together as hypothesized so was completely removed from the analysis due to a lack of consistency and validity; Gruzd, Staves, and Wilk (2012) also predicted and evidenced a negative relationship between FC and BI in terms of social media use by academics.

H5: Hedonic Motivation (HM) will not be positively related to BI in the adoption of CRS.

We define HM, a new construct in the UTATU2 model incorporated from motivation theory, in our research as the enjoyment students derive from using CRS. According to Venkatesh et al. (2012), it is defined as the fun or 
enjoyment derived from using a technology and plays an important role in determining technology acceptance and use. A review of 79 UTAUT2 empirical studies revealed that only 46 studies (58\%) utilized HM, while the remaining $33(42 \%)$ omitted the construct (Tamilmani, Rana, Prakasam, \& Dwivedi, 2019), so further study on HM influence is necessary. In the higher education context, Yang (2013) found negatively moderated relationships between HT and intention to adopt m-learning, suggesting the negative influence of mobile device technical limitations (slow network speeds, small screens and keyboard) and use of mobile devices for hedonic purposes, such as gaming or texting friends; similar results were evidenced by Lewis et al. (2013) in terms of classroom technology use. Nevertheless, Faizan et al. (2016) established a strong relationship between HM and BI regarding classroom collaboration technology, implying that students can interact with other students, which is more entertaining and enjoyable when compared to traditional lectures; according to some authors (Cotner et al., 2008; Stowell \& Nelson, 2007), instant feedback is enjoyable; learning by means of videos was another educational technology where HM significantly predicted BI (Aria \& Archer, 2018); finally, teamwork and gamification, a possible way to use CRS, also increases entertainment and enjoyment (Hung, 2017).

H6: Trust (TR) will have a significant positive influence on BI.

We integrated TR, defined as the emotional state that encouraged $\mathrm{X}$ to trust $\mathrm{Y}$, based on the satisfactory functioning of Y (Singh \& Sinha, 2020), into our research model even though it was not part of the original UTATU2 model, viewing CRS as technology that functioned reliably and precisely so students could trust that their answers had been correctly noticed by teachers and their voices heard. Because CRS are new for many institutions, teachers and students easily distrust its accuracy and reliability (White, Syncox, \& Alters, 2011). In terms of young users of social networks (Sledgianowski \& Kulviwat, 2009) and mobile network gaming (Baabdullah et al., 2019), trust was also evidenced to significantly affect intention to use said technology. In the educational context, it is crucial that students trust clicker technology, especially if responses are supposed to be collected accurately and anonymously (Bojinova \& Oigara, 2013; Woelk, 2008).

H7: Habit (HT) will have a significant positive influence on student intention to use CRS (BI).

HT, added to the UTAUT2 model because people tend to react automatically as a consequence of learning, is related to but different to experience, which is described by Venkatesh et al. (2012) as a necessary but not sufficient condition for the formation of HT. The significant impact of HT on BI was confirmed by Baudier, Ammi, and Deboeuf-Rouchon (2018) with regard to acceptance of the "Smart Home Concept" among digital natives. In the educational setting, habutial student use of technology has received limited attention, calling for further research (Ain et al., 2016). Lewis et al. (2013) evidenced HT's significant impact on BI in the higher education environment, but not on UB. According to Faizan et al. (2016), HT significantly predicts student intention to use ICT (BI) and use it (UB) in the classroom. Similar results were confirmed regarding e-learning environments by Mehta et al. (2019).

H8. HT will have a significant positive influence on student use of CRS i.e. their use behavior.

H9: Facilitating Conditions (FC) will have a significant positive influence on student use of CRS.

The facilitating conditions construct in the UTAUT model directly influences use behavior, namely to the degree to which individuals believe that organizational and technical infrastructures exist to support system use (Venkatesh et al., 2003). FC was found to be a stronger predictor of use beaviour (Chauhan \& Jaiswal, 2016) with regard to business software training; Ain et al. (2016) evidenced FC's significant positive impact on UB but not on BI when researching LMS use; Raman and Don (2013) evidenced FC's significant and positive impact on LMS use by students at a university in Malaysia; and Faizan et al. (2016) confirmed the same for student use of diverse ICT in the classroom.

H10. Behaviour Intention (BI) will have a significant positive influence on student use of CRS.

Finally, we crucially endeavoured to ascertain the relationship between BI and UB, where BI is defined as the degree to which a person has formulated conscious plans to behave or not to behave in the future. The UTATU2 model suggested that high BI to use technology positively influences its later use. However, there was a lack of research on the UB construct and aforementioned relationship. Nevertheless, the relationship between BI and UB, the research focus of this paper, has been confirmed by the literature (Macedo, 2017; Ramírez-Correa, Rondán-Cataluña, Arenas-Gaitán, \& Martín-Velicia, 2019), including that from the field of education. For example, Faizan et al. (2016) confirmed the significance of said relationship, and suggested that the greater the perceived intention to use ICT by students, the greater the chance of actual use. Raman and Don (2013) obtained similar results for the use of LMS by students. Research by Baptista and Oliveira (2015) even showed that cultural moderators, such as user individualism and uncertainty avoidance, significantly influence the positive relationship between BI and UB. 


\section{Method}

\subsection{Participants}

The participants in this study were students, aged between 19 and 22, enrolled in two undergraduate social science higher education programs (1st cycle), selected from one course in each year of boths programs, at the University of Ljubljana, Slovenia, who were questioned about the use of CRS in their classrooms. Students used clickers, smart phones and different CRS software during their courses.

\subsection{The Use of CRS in the Classroom}

The participating students used CRS during classes at least once during a course each semester. CRS was used during or at the end of each class to assess lecture progress and verify understanding. No participation credit, in the form of rewards or penalties, was given for correct answers because this could negatively affect collaborative learning (Kulikovskikh et al., 2017). Multiple response questions, with one or multiple answers being correct, related to the content of the lesson, were used: firstly, questions were shown using an LCD projector and time given for students to respond; secondly, cumulative answer results were shown at the end of each answering period, with discussion on results following; finally, the correct answer was usually revealed, and additional explanation given by the teacher if needed.

\subsection{CRS Polling Devices and Questions}

Teachers informed students about CRS, describing processes and the devices used, at the beginning of each course, encouraging students to participate and ensuring response anonymity. In some classes, students used TurningPoint radio frequency clickers with numerical buttons provided by the faculty, which were distributed to students at the beginning of each class and collected at lesson's end; teachers used USB radio frequency receivers connected to classroom computers and PowerPoint using a TurningPoint add-in. In other classes, students installed and used smart phone applications on their mobile phones, either TurningPoint or Kahoot! The use of mobile phones was allowed for the purpose of polling but not otherwise promoted during classes.

Most questions provided four possible options, with one or more correct answers. In some classes, team assignment questioning was enabled by CRS, with students selecting teams; at the end of the lesson, results were shown, including best individuals, best teams, and most valuable team players' gamification of the active learning process.

\subsection{Survey Instrument and Data Collection}

Data for this research study were collected using a survey questionnaire based on the items defined by Venkatesh et al. (2012) in the original UTAUT2 model, plus an additional four questions related to trust. The questionnaire, written in Slovenian and proofed by two English language lecturers, was composed of 31 closed questions, and measured with ordinal scales using a 7-point Likert-type scale from "(1) Strongly disagree" to "(7) Strongly agree" (see Appendix); the questions were posited into seven groups reflecting the UTAUT2 model's constructs of PE, EE, SI, FC, HT, TR, HM, and BI, including one question addressing UB.

The questionnaire was distributed to students during one of the final lessons of the semester, accompanied by an explanation of the nature of the research and questionnaire anonymity, and students asked to rate their attitude toward CRS technology. The students had previously used similar questionnaires during their studies so were familiar with its form, so took no more than 10 minutes to complete our's. If questions arose during questionnaire completion, teachers provided clarification.

\section{Results}

\subsection{The Measurement Model}

We received 201 completed questionnaires and the data were analyzed using the Statistical Package for Social Sciences (IBM SPSS v.24) and structural equation modeling (SEM) (IBM AMOS v.24) software, SEM being used because it is the most appropriate tool when theory or a priori guidelines allow researchers to posit relationships among observed and latent variables in the model (Schumacker \& Lomax, 2015, p. 3). AMOS was used for covariance-based SEM, when the research objective was theory testing and confirmation, while another oft-used SEM software package Smart PLS (Partial Least Square), was used when the research objective was prediction and theory development (Hair, Hult, Ringle, \& Sarstedt, 2016, p. 32).

We first tested our model for reliability and validity using Confirmatory Factor Analysis (CFA) and the Maximum-likelihood Method to certify construct measurement validity and reliability before drawing any conclusions, including construct and discriminant validity, where each construct was modeled as a reflective latent 
construct accounting for its indicators. In order to assess convergent validity's utility as a method for testing construct validity three criteria were tested: 1 ) each item's loading $(\lambda)$ to be statistically significant and larger than 0.50 (Hair, Black, Babin, \& Anderson, 2013, p. 618); 2) composite reliability $\left(\rho_{c}\right)$, representing the shared variance among a set of observed variables for each latent construct, to be larger than 0.70 with average variance extracted (AVE) for each latent construct to be larger than 0.50 (Fornell \& Larcker, 1981); 3) Cronbach's alpha's internal consistency reliability measures to be above the recommended level of 0.7 for all constructs. Discriminant validity, indicating the extent to which a given construct differs from other constructs, was checked on the basis of the rule that the square root of every AVE should exceed the correlation between any pair of latent constructs (Fornell \& Larcker, 1981). With regard to criteria, all item loadings qualified as "good", ranging from 0.55 to 0.91 , and significant when $\mathrm{p}<0.001$; composite reliability ranged from 0.752 to 0.904 , with AVE from 0.509 to 0.725 . All constructs had a Cronbach's alpha above 0.7 , suggesting construct reliability. These results demonstrated that the conditions for reliability, construct and discriminant validity were satisfied.

\subsection{Hypothesis Testing and Validation}

AMOS generated a strucutal model based on the aforementioned data (Figure 2)

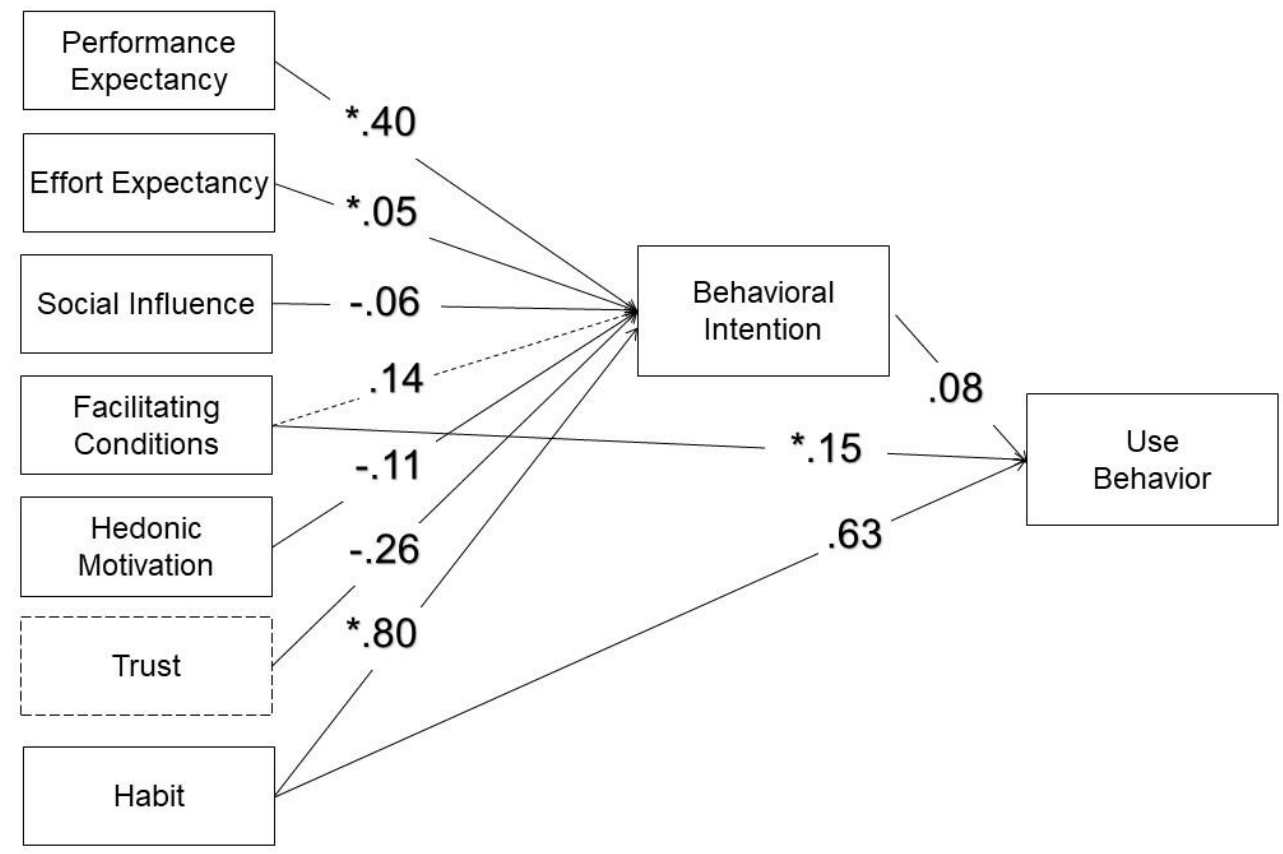

Figure 2. SEM model (standardized estimates of relationships, with * representing significant values).

The structural model was examined using SEM to evaluate (a) data fit with structural model and (b) hypothesized relationships on the basis of algebraic sign, magnitude, and structural path significance, results revealing the following fit values: $\chi 2 / \mathrm{df}=1.512$, TLI $=.943, \mathrm{CFI}=.956$, RMSEA $=.051$, which accord with suggested benchmark values for good structural model fit. Thus, good data fit with the structural model was achieved. The relationships between the proposed structural paths were assessed in terms of statistical significance and standardized loading.

Table 1 summarizes our structural model results and proposed hypothetical relationships for variables. The structural model results showed that five hypothesized relationships were supported, i.e. between PE (H1), TR (H6) and HT (H7), between CRS and BI, and between FC (H8), HT (H9), and CRS and UB. 
Table 1. Hypothesis testing results

\begin{tabular}{|c|c|c|c|c|c|c|c|}
\hline & & & $\begin{array}{c}\text { Standardized } \\
\text { estimate } \beta\end{array}$ & S.E. & C.R. & $p$ & Remarks \\
\hline$\overline{\mathrm{H} 1}$ & $\mathrm{BI}$ & $\leftarrow \mathrm{PE}$ & 0.399 & 0.099 & 4.531 & $* * *$ & Supported \\
\hline $\mathrm{H} 2$ & $\mathrm{BI}$ & $\leftarrow \quad \mathrm{EE}$ & 0.053 & 0.129 & 0.763 & 0.445 & Not supported \\
\hline $\mathrm{H} 3$ & $\mathrm{BI}$ & $\leftarrow \mathrm{SI}$ & -0.056 & 0.07 & -0.683 & 0.495 & Not supported \\
\hline $\mathrm{H} 4$ & $\mathrm{BI}$ & $\leftarrow \mathrm{FC}$ & 0.135 & 0.112 & 1.863 & 0.062 & Not supported \\
\hline H5 & BI & $\leftarrow \mathrm{HM}$ & -0.107 & 0.118 & -0.948 & 0.343 & Not supported \\
\hline H6 & BI & $\leftarrow \mathrm{TR}$ & -0.260 & 0.075 & -3.797 & $* * *$ & Supported \\
\hline $\mathrm{H} 7$ & BI & $\leftarrow \mathrm{HT}$ & 0.801 & 0.218 & 4.331 & $* * *$ & Supported \\
\hline $\mathrm{H} 8$ & UB1 & $\leftarrow \mathrm{HT}$ & 0.634 & 0.276 & 4.326 & $* * *$ & Supported \\
\hline H9 & UB1 & $\leftarrow \mathrm{FC}$ & 0.151 & 0.147 & 2.509 & 0.012 & Supported \\
\hline $\mathrm{H} 10$ & UB1 & $\leftarrow \mathrm{BI}$ & 0.078 & 0.208 & 0.6 & 0.549 & Not supported \\
\hline
\end{tabular}

Model quality was assessed using the coefficient of determination (R2), which represents the amount of explained variance of each endogenous latent variable: the research model explains $89 \%$ of total variance in behavioral intention and 59\% of CRS use behavior regarding CRS; the high R2 value substantiates the model's predictive validity.

\section{Discussion}

Previous research on CRS had failed to fully explore the factors that influence CRS behavioral intention and use behavior within the active learning context; to fill this research gap, we analyzed these factors and tested the UTAUT model's appropriateness in terms of CRS adoption (Venkatesh et al., 2012): the model evidenced adequate fit based on the questionnaire collected data and supported the UTAUT2 model's validity with the augmented construct of trust in CRS. It is also important to stress that the model is based on the responses of social science program students, wheras prior research had mainly been conducted in technical and scientific subject settings (Blasco-Arcas et al., 2013), which includes the context of IT supported active learning research.

Our statistical results indicate support for hypotheses $\mathrm{H1}, \mathrm{H} 6$ and H7, though some difference exists regarding the weight of the coefficient paths for each latent variable in predicting BI. Firstly, student PE was significantly correlated with BI (H1) with a high $\beta$ value $(\beta=0.395$; $p<0.001$ ), which is consistent with previous research (See Table 1). Results suggest that if people fail to see the qualities and advantages associated with CRS, they may be unwilling to use said new technology, implying that the extent to which CRS provides possibilities for students to achieve study goals is significantly linked to their intention to use CRS. However, Blasco-Arcas et al. (2013) stress this is only achieved with adequate pedagogical focus and appropriate CRS integration into the teaching process. The results are also consistent with Faizan et al. (2016), who stated that students with higher PE intend to make better use of the technology than those with low expectations. Alalwan (2018) also found that the technology's interactivity level is positively linked to PE, indicating that CRS enabled interactivity increases CRS use intention. Secondly, student HT was found to be most significant $(\beta=0.805 ; \mathrm{p}<0.001)$ in explaining BI to use CRS (H7), though its effect was small; the construct of "Habit" also had the strongest effect on "Intention to Use" in the research of other authors (Baudier et al., 2018); similar research on behavioral intention to use a specific IT in education by Mehta et al. (2019) evidenced that prior experience with such IT is an important factor in determining learner behavioral intention to use e-learning irrespective of context; therefore, forming active learning habits using CRS in one course leads to increased intention to use CRS based active learning in other courses. Thirdly, the influence of TR, our study's newly augmented construct, proved to significantly affect BI (H6) $(\beta=-0.26 ; p<0.001)$; trust in CRS technology had been highlighted as a parameter that maximizes active participation (Woelk, 2008), and by others (Singh \& Sinha, 2020) in relation to more critical technology intention, and this may be because CRS technology reliability and accuracy has much improved in recent decades (White et al., 2011) and student responses were not recorded as grades or partial grades, making the activity more relaxed.

H8 and H9 were also supported with regard to UB impact. Firstly, FC have a small but significant impact ( $\beta=0.151$; $\mathrm{p}<0.05)$ on UB (H9), as previously predicted by the UTAUT model (Venkatesh et al., 2003) and confirmed by 
various UTATU2 models (Macedo, 2017; Venkatesh et al., 2012). The results also align with the findings of other authors/researchers in the educational context (Faizan et al., 2016; Raman \& Don, 2013). Appropriate FC ensured that students frequently used the technology and recieved assistance when necessary. FC2 $(\beta=0.86)$ evidenced the highest loading within this construct, indicating that students needed adequate knowledge about the technology to willingly use it. Secondly, the HT construct (H8) $(\beta=0.629 ; p<0.001)$ most greatly affected UB, in a similar fashion to others findings (Baabdullah et al., 2019; Baptista \& Oliveira, 2015; Ramírez-Correa et al., 2019). Although students did not have a lot of experience with CRS, they believed that the more they used it, the more it would become habitual and easily performed.

Results also evidenced that EE, HM, FC, and SI were not significant predictors of BI to use CRS, confirming H4, that FC did not have a significant effect on BI but did on UB. So, even if students perceive that facilitating conditions are adequate, this will not affect their perception of UB until they start using CRS. Finally, results showed that BI did not have a significant impact on CRS use, as with Baptista and Oliveira (2015). Therefore, if students fail to directly or indirectly express their intention to use a technology, it does not mean that they will not actually use it, or vice versa.

\subsection{Results Implications}

Several implications can be drawn from the findings. It can be concluded that the UTAUT2 model was applicable to CRS technology adaption and use, and could be used in higher education institutions that test student behavioral intention to use CRS, or plan its implementation. Blasco-Arcas et al. (2013) confirmed that active collaborative learning as a result of using clickers improves student engagement. Therefore, in order to achieve such engagement, institutions should ensure a pedagogical environment that improves performance and promotes CRS use; in such environments, students develop appropriate habits, improve student achievement and attainment of student study goals increase study efficiency, and most attracted students to such courses. Once students start using CRS, facilitating conditions play a significant role; institutions should provide adequate resources and support at all times.

Even though, social environment is important for young people, results showed it not significantly important when considering the behavioral intention to use CRS. Furthermore, EE is insignificant, indicating that contemporary CRS technology does not challenge this generation. Although CRS technology's gamification options might increase enjoyment whilst using it, the results evidence insignificant HM impact; even when technology does not provide enjoyment features or teachers are unable to use said technolgy, impact is insignificant.

\subsection{Limitations and Further Research}

This research's limitations offer opportunities for future research; it identified the important factors influencing behavioral intention and use behavior in terms of CRS technology in higher education. Future research could further explore CRS's unique variables, such as the influence of individual factors on students understanding and examination scores. Furthermore, it could link the factors influencing CRS technology behavioral intention and use behavior to different pedagogical strategies. Additionally, this research did not test the influence of moderators such as age, gender, and experience, so future research should examine these influencing factors, including the different education levels and, therefore, age and its influence on CRS adoption and use.

This study was also limited to the higher education context, but CRS is often used in business environments. It would be useful to test the model regarding CRS use at conferences, business events and adult training courses. Moreover, caution should be exercised regarding our findings because we analyzed cases where clickers and smart phones were used, but model fit for each device type was unproved. It would be useful for future research to examine the impact of device type: while clickers have a limited number of functionalities and smartphones offer so much more, the latter present the risk of distraction because of multifunctionaility. Lastly, we did not study Price Value, but in higher education environments where students must purchase or rent CRS devices or licenses, this UTAUT2 construct might significantly affect BI and UB, as evidenced on online app stores, where dissatisfied users often complain about the price and reliability of CRS products.

\section{Conclusion}

The effectiveness of teachers or presenters at conferences, business events, and the like, ultimately lies in how well their listeners understand and apply the addressed concepts, as stated by Lewis et al. (2013); ICT greatly benefits learning facilitators, though success primarily lies in the hands of the students; therefore, it is important to be aware of what influences student ICT acceptance and use, namely CRS in our case.

This study effectively utilized the UTAUT2 model as a foundation for examining the various factors influencing higher education student CRS behavioral intention and use, finding CRS technology user-friendly for these digital 
natives; moreover, habit proved crucial in terms of intention to and actual use of CRS. Consequently, ensuring the appropriate conditions for introducing and maintaining technology at all times is a constant and demanding task for all stakeholders, be they teachers, IT support staff, organizational managers, or leaders.

Overall, the findings provide valuable insight for all stakeholders in educational environments, especially those tasked with efficient and effective teaching, and this is known to be influenced by ICT pervasiveness. Even so, although CRS is viewed as an important tool for facilitating better and active learning, we agree with the other researchers who stress that pedagogical excellence is the key to learning success.

\section{References}

Ain, N., Kaur, K. \& Waheed, M. (2016). The influence of learning value on learning management system use: An extension of UTAUT2. Information Development, 32(5), 1306-1321. https://doi.org/10.1177/0266666915597546

Alalwan, A. A. (2018). Investigating the impact of social media advertising features on customer purchase intention. International Journal of Information Management, 42, 65-77. https://doi.org/10.1016/j.ijinfomgt.2018.06.001

Andersson, C. \& Palm, T. (2017). The impact of formative assessment on student achievement: A study of the effects of changes to classroom practice after a comprehensive professional development programme. Learning and Instruction, 49, 92-102. https://doi.org/10.1016/j.learninstruc.2016.12.006

Aria, R. \& Archer, N. (2018). Using an educational video vs. In-person education to measure patient perceptions of an online self-management support system for chronic illness. Computers in Human Behavior, 84(4), 162-170. https://doi.org/10.1016/j.chb.2018.01.041

Baabdullah, A. M., Alalwan, A. A., Rana, N. P., Kizgin, H. \& Patil, P. (2019). Consumer use of mobile banking (M-Banking) in Saudi Arabia: Towards an integrated model. International Journal of Information Management, 44, 38-52. https://doi.org/10.1016/j.ijinfomgt.2018.09.002

Baptista, G. \& Oliveira, T. (2015). Understanding mobile banking: The unified theory of acceptance and use of technology combined with cultural moderators. Computers in Human Behavior, 50(5), 418-430. https://doi.org/10.1016/j.chb.2015.04.024

Baudier, P., Ammi, C. \& Deboeuf-Rouchon, M. (2018). Smart home: Highly-educated students' acceptance. Technological Forecasting and Social Change. https://doi.org/10.1016/j.techfore.2018.06.043

Berry, J. (2009). Technology support in nursing education: Clickers in the classroom. Nursing Education Perspectives, 30(5), 295-298.

Black, P. \& Wiliam, D. (1998). Assessment and Classroom Learning. Assessment in Education: Principles, Policy \& Practice, 5(1), 7-74. https://doi.org/10.1080/0969595980050102

Blasco-Arcas, L., Buil, I., Hernández-Ortega, B. \& Sese, F. J. (2013). Using clickers in class. The role of interactivity, active collaborative learning and engagement in learning performance. Computers \& Education, 62, 102-110. https://doi.org/10.1016/j.compedu.2012.10.019

Bojinova, E. \& Oigara, J. (2013). Teaching and Learning with Clickers in Higher Education. International Journal of Teaching and Learning in Higher Education, 25(2), 154-165.

Bright, D. R., Reilly Kroustos, K. \& Kinder, D. H. (2013). Classroom response systems during case-based discussions: A pilot study of student perceptions. Currents in Pharmacy Teaching and Learning, 5(5), 410-416. https://doi.org/10.1016/j.cptl.2013.06.007

Burns, R. A. (1985). Information Impact and Factors Affecting Recall. Proceedings of the Annual National Conference on Teaching Excellence and Conference of Administrators. Austin, Texas.

Castillo-Manzano, J. I., Castro-Nuño, M., López-Valpuesta, L., Sanz-Díaz, M. T. \& Yñiguez, R. (2016). Measuring the effect of CRS on academic performance: A global meta-analysis. Computers \& Education, 96, 109-121. https://doi.org/10.1016/j.compedu.2016.02.007

Chan, T. F. I., Borja, M., Welch, B. \& Batiuk, M. E. (2016). Predicting the probability for faculty adopting an audience response system in higher education. Journal of Information Technology Education: Research, 15(1), 395-407. https://doi.org/10.28945/3548

Chauhan, S. \& Jaiswal, M. (2016). Determinants of acceptance of ERP software training in business schools: Empirical investigation using UTAUT model. The International Journal of Management Education, 14(3), 
248-262. https://doi.org/10.1016/j.ijme.2016.05.005

Cheung, G., Chan, K., Brown, I. \& Wan, K. (2016). Teachers' Knowledge and Technology Acceptance: A Study on the Adoption of Clickers. Proceedings of the 11th International Conference on E-Learning, 46. Kuala Lumpur, Malaysia: Academic Conferences International Limited.

Chien, Y.-T., Chang, Y.-H. \& Chang, C.-Y. (2016). Do we click in the right way? A meta-analytic review of clicker-integrated instruction. Educational Research Review, 17, 1-18. https://doi.org/10.1016/j.edurev.2015.10.003

Cotner, S. H., Fall, B. A., Wick, S. M., Walker, J. D. \& Baepler, P. M. (2008). Rapid feedback assessment methods: Can we improve engagement and preparation for exams in large-enrollment courses? Journal of Science Education and Technology, 17(5), 437-443. https://doi.org/10.1007/s10956-008-9112-8

Daniel, T. \& Tivener, K. (2016). Effects of Sharing Clickers in an Active Learning Environment. Educational Technology \& Society, 19, 260-268. Retrieved from https://www.jstor.org/stable/jeductechsoci.19.3.260

De Gagne, J. C. (2011). The impact of clickers in nursing education: A review of literature. Nurse Education Today, 31(8), 34-40. https://doi.org/10.1016/j.nedt.2010.12.007

DeBourgh, G. A. (2008). Use of classroom "clickers" to promote acquisition of advanced reasoning skills. Nurse Education in Practice, 8(2), 76-87. https://doi.org/10.1016/j.nepr.2007.02.002

Efstathiou, N. \& Bailey, C. (2012). Promoting active learning using Classroom response System in large bioscience classes. Nurse Education Today, 32(1), 91-95. https://doi.org/10.1016/j.nedt.2011.01.017

Esteva Armida, E. (2008). Adoption process for VOIP: The influence of trust in the UTAUT model (Ph.D., Purdue University). Retrieved from https://search.proquest.com/docview/304501954/abstract/A51A3C471CB24B24PQ

Faizan, A., Pradeep Kumar, N. \& Kashif, H. (2016). An assessment of students' acceptance and usage of computer supported collaborative classrooms in hospitality and tourism schools. Journal of Hospitality, Leisure, Sport \& Tourism Education, 18, 51-60. https://doi.org/10.1016/j.jhlste.2016.03.002

Farag, D. M., Park, S. \& Kaupins, G. (2015). Faculty Perceptions of the Adoption and Use of Clickers in the Legal Studies in Business Classroom. Journal of Education for Business, 90(4), 208-216. https://doi.org/10.1080/08832323.2015.1014459

Fornell, C. \& Larcker, D. F. (1981). Evaluating Structural Equation Models with Unobservable Variables and Measurement Error. Journal of Marketing Research, 18(1), 39-50. https://doi.org/10.2307/3151312

Green, A. J., Chang, W., Tanford, S. \& Moll, L. (2015). Student Perceptions towards Using Clickers and Lecture Software Applications in Hospitality Lecture Courses. Journal of Teaching in Travel \& Tourism, 15(1), 29-47. https://doi.org/10.1080/15313220.2014.999738

Gruzd, A., Staves, K. \& Wilk, A. (2012). Connected scholars: Examining the role of social media in research practices of faculty using the UTAUT model. Computers in Human Behavior, 28(6), 2340-2350. https://doi.org/10.1016/j.chb.2012.07.004

Hair, J. F., Black, W. C., Babin, B. J. \& Anderson, R. E. (2013). Multivariate Data Analysis: Pearson New International Edition (Seventh edition). Harlow: Pearson Education Limited.

Hair, J. F., Hult, G. T. M., Ringle, C. M. \& Sarstedt, M. (2016). A Primer on Partial Least Squares Structural Equation Modeling (Second edition). Los Angeles: SAGE Publications, Inc.

Hsu, H. (2013). The Acceptance of Moodle: An Empirical Study Based on UTAUT. Creative Education, 3(8), 44-46. https://doi.org/10.4236/ce.2012.38B010

Hubbard, J. K. \& Couch, B. A. (2018). The positive effect of in-class clicker questions on later exams depends on initial student performance level but not question format. Computers \& Education, 120, 1-12. https://doi.org/10.1016/j.compedu.2018.01.008

Hung, H.-T. (2017). Clickers in the flipped classroom: Bring your own device (BYOD) to promote student learning. Interactive Learning Environments, 25(8), 983-995. https://doi.org/10.1080/10494820.2016.1240090

Hunsu, N. J., Adesope, O. \& Bayly, D. J. (2016). A meta-analysis of the effects of audience response systems (clicker-based technologies) on cognition and affect. Computers \& Education, 94, 102-119. https://doi.org/10.1016/j.compedu.2015.11.013 
Judson, E. \& Sawada, D. (2002). Learning from past and present: Electronic response systems in college lecture halls. Journal of Computers in Mathematics and Science Teaching, 21(2), 167-181.

Kay, R. H. (2009). Examining gender differences in attitudes toward interactive classroom communications systems (ICCS). Computers \& Education, 52(4), 730-740. https://doi.org/10.1016/j.compedu.2008.11.015

Kay, R. H. \& LeSage, A. (2009). Examining the benefits and challenges of using classroom response systems: A review of the literature. Computers \& Education, 53(3), 819-827. https://doi.org/10.1016/j.compedu.2009.05.001

Kulikovskikh, I. M., Prokhorov, S. A. \& Suchkova, S. A. (2017). Promoting collaborative learning through regulation of guessing in clickers. Computers in Human Behavior, 75(5), 81-91. https://doi.org/10.1016/j.chb.2017.05.001

Lantz, M. E. \& Stawiski, A. (2014). Effectiveness of clickers: Effect of feedback and the timing of questions on learning. Computers in Human Behavior, 31(1), 280-286. https://doi.org/10.1016/j.chb.2013.10.009

Lewis, C. C., Fretwell, C. E., Ryan, J. \& Parham, J. B. (2013). Faculty use of established and emerging technologies in higher education: A unified theory of acceptance and use of technology perspective. International Journal of Higher Education, 2(2), 22-34. https://doi.org/10.5430/ijhe.v2n2p22

Macedo, I. M. (2017). Predicting the acceptance and use of information and communication technology by older adults: An empirical examination of the revised UTAUT2. Computers in Human Behavior, 75(5), 935-948. https://doi.org/10.1016/j.chb.2017.06.013

Maldonado, U. P. T., Khan, G. F., Moon, J. \& Rho, J. J. (2011). E-learning motivation and educational portal acceptance in developing countries. Online Information Review, 35(1), 66-85. https://doi.org/10.1108/14684521111113597

Mehta, A., Morris, N. P., Swinnerton, B. \& Homer, M. (2019). The Influence of Values on E-learning Adoption. Computers \& Education, 141, 103617. https://doi.org/10.1016/j.compedu.2019.103617

Nicol, A. A., Owens, S. M., Le Coze, S. S., MacIntyre, A. \& Eastwood, C. (2018). Comparison of high-technology active learning and low-technology active learning classrooms. Active Learning in Higher Education, 19(3), 253-265. https://doi.org/10.1177/1469787417731176

Oswald, K. M., Blake, A. B. \& Santiago, D. T. (2014). Enhancing Immediate Retention with Clickers Through Individual Response Identification. Applied Cognitive Psychology, 28(3), 438-442. https://doi.org/10.1002/acp.3010

Pavlou, P. A. (2003). Consumer Acceptance of Electronic Commerce: Integrating Trust and Risk with the Technology Acceptance Model. International Journal of Electronic Commerce, 7(3), 101-134. https://doi.org/10.1080/10864415.2003.11044275

Pituch, K. A. \& Lee, Y. (2006). The Influence of System Characteristics on e-Learning Use. Computers \& Education, 47(2), 222-244. https://doi.org/10.1016/j.compedu.2004.10.007

Pratton, J. \& Hales, L. (1986). The effects of active participation on student learning. Journal of Educational Research, 79, 210-215. https://doi.org/10.1080/00220671.1986.10885679

Prince, M. (2004). Does active learning work? a review of the research. Journal of Engineering Education, 93, 223-231. https://doi.org/10.1002/j.2168-9830.2004.tb00809.x

Raman, A. \& Don, Y. (2013). Preservice Teachers' Acceptance of Learning Management Software: An Application of the UTAUT2 Model. International Education Studies, 6(7), 157-164. https://doi.org/10.5539/ies.v6n7p157.

Ramírez-Correa, P., Rondán-Cataluña, F. J., Arenas-Gaitán, J. \& Martín-Velicia, F. (2019). Analysing the acceptation of online games in mobile devices: An application of UTAUT2. Journal of Retailing and Consumer Services, 50, 85-93. https://doi.org/10.1016/j.jretconser.2019.04.018

Rana, N. P. \& Dwivedi, Y. K. (2016). Using clickers in a large business class: Examining use behavior and satisfaction. Journal of Marketing Education, 38(1), 47-64. https://doi.org/10.1177/0273475315590660

Rivkin, A., Yin, H., Borno, L., Fabbio, K., Kugler, A., Maltz, F. N. \& Najib, J. (2013). Revising senior pharmacy grand rounds to incorporate longitudinal board review to prepare students for licensing examination. Currents in Pharmacy Teaching and Learning, 5(3), 236-240. https://doi.org/10.1016/j.cptl.2012.12.002

Schackow, T. E., Chavez, M., Loya, L. \& Friedman, M. (2004). Audience response system: Effect on learning in 
family medicine residents. Family Medicine, 36(7), 496-504.

Schumacker, R. E. \& Lomax, R. G. (2015). A Beginner's Guide to Structural Equation Modeling: Fourth Edition (4 edition). New York, NY: Routledge.

Shapiro, A. M., Sims-Knight, J., O’Rielly, G. V., Capaldo, P., Pedlow, T., Gordon, L. \& Monteiro, K. (2017). Clickers can promote fact retention but impede conceptual understanding: The effect of the interaction between clicker use and pedagogy on learning. Computers \& Education, 111, 44-59. https://doi.org/10.1016/j.compedu.2017.03.017

Singh, N. \& Sinha, N. (2020). How perceived trust mediates merchant's intention to use a mobile wallet technology. Journal of Retailing and Consumer Services, 52, 101894. https://doi.org/10.1016/j.jretconser.2019.101894

Sledgianowski, D. \& Kulviwat, S. (2009). Using social network sites: The effects of playfulness, critical mass and trust in a hedonic context. Journal of Computer Information Systems, 49(4), 74-83. https://doi.org/10.1080/08874417.2009.11645342

Spark, L. L. \& De Klerk, D. (2015). Using clickers in lectures: A study of first experiences. 9th Annual Teaching and Learning in Higher Education Conference, 199. Durban, South Africa.

Stowell, J. R. \& Nelson, J. M. (2007). Benefits of electronic audience response systems on student participation, learning and emotion. Teaching of Psychology, 34, 253-258. https://doi.org/10.1080/00986280701700391

Sun, J. C.-Y. (2014). Influence of polling technologies on student engagement: An analysis of student motivation, academic performance, and brainwave data. Computers \& Education, 72, 80-89. https://doi.org/10.1016/j.compedu.2013.10.010

Tamilmani, K., Rana, N. P., Prakasam, N. \& Dwivedi, Y. K. (2019). The battle of Brain vs. Heart: A literature review and meta-analysis of "hedonic motivation" use in UTAUT2. International Journal of Information Management, 46, 222-235. https://doi.org/10.1016/j.ijinfomgt.2019.01.008

Tin, T. B. (2009). Features of the most interesting and the least interesting postgraduate second language acquisition lectures offered by three lecturers. Language and Education, 23(2), 117-135. http://dx.doi.org/10.1080/09500780802152770

Venkatesh, V., Morris, M. G., Davis, G. B. \& Davis, F. D. (2003). User Acceptance of Information Technology: Toward a Unified View. MIS Quarterly, 27(3), 425-478.

Venkatesh, V., Thong, J. Y. L. \& Xu, X. (2012). Consumer Acceptance and Use of Information Technology: Extending the Unified Theory of Acceptance and Use of Technology. MIS Quarterly, 36(1), 157-178. https://doi.org/10.2307/41410412

Werf, M. V. D. \& Sabatier, G. (2009). The College of 2020: Students. Cleveland, Ohio: Kelvin Smith Library, Case Western Reserve University.

White, P., Syncox, D. \& Alters, B. (2011). Clicking for grades? Really? Investigating the use of clickers for awarding grade-points in post-secondary education. Interactive Learning Environments, 19(5), 551-561. https://doi.org/10.1080/10494821003612638

Woelk, K. (2008). Optimizing the Use of Personal Response Devices (Clickers) in Large-Enrollment Introductory Courses. Journal of Chemical Education, 85(10), 1400. https://doi.org/10.1021/ed085p1400

Wu, I.-L. \& Chen, J.-L. (2005). An Extension of Trust and TAM Model with TPB in the Initial Adoption of On-line Tax: An Empirical Study. Int. J. Hum -Comput. Stud., 62(6), 784-808. https://doi.org/10.1016/j.ijhcs.2005.03.003

Yang, S. (2013). Understanding undergraduate students' adoption of mobile learning model: A perspective of the extended UTAUT2. Journal of Convergence Information Technology, 8(10), 969. https://doi.org/10.4156/jcit.vol8.issue10.118

Yuan, S., Ma, W., Kanthawala, S. \& Peng, W. (2015). Keep Using My Health Apps: Discover Users' Perception of Health and Fitness Apps with the UTAUT2 Model. Telemedicine and E-Health, 21(9), 735-741. https://doi.org/10.1089/tmj.2014.0148 


\section{Appendix}

The questionnaire used in the survey:

- PE1: I find this technology useful in my studies.

- PE2: Using this technology increases my chances of achieving my study goals.

- PE3: Using this technology helps me learn more quickly.

- PE4: Using this technology increases my productivity.

- EE1: Learning how to use this technology is easy for me.

- EE2: My interaction with this technology is clear and understandable.

- $\quad$ EE3: I find this technology easy to use.

- EE4: It is easy for me to become skillful at using this technology.

- SI1: People who are important to me think that I should use this technology.

- $\quad$ SI2: People who influence my studies think that I should use this technology.

- SI3: People whose opinions I value prefer that I use this technology.

- SI4: I would use this technology because my schoolmates use it.

- $\quad \mathrm{FC1}$ : I have the resources necessary to use this technology.

- FC2: I have the knowledge necessary to use this technology.

- FC3: This technology is compatible with other technologies I use.

- FC4: I can get help from others if I have difficulty using this technology.

- HM1: Using this technology is fun.

- HM2: Using this technology is enjoyable.

- HM3: Using this technology is exciting.

- HT1: Using this technology has become habitual.

- HT2: I am addicted to using this technology.

- HT3: I want to use this technology in my studies.

- HT4: Using this technology in other courses would feel natural to me.

- TR1: I believe this technology is precise.

- TR2: I think I trust this technology.

- TR3: I think this technology is reliable.

- TR4: I think this technology is designed for my needs.

- BI1: I intend to continue using this technology in the future.

- BI2: I plan to continue using this technology in my studies.

- BI3: If available, I will regularly use this technology.

- UB1: When I have the chance, I always use this technology.

Scale: 1 - almost never true, 2 - usually not true, 3 - often not true, 4 - occasionally true, 5 - often true, 6 - usually true, 7 - almost always true 